\title{
Identification of geographical gaps in the pearl millet germplasm conserved at ICRISAT genebank from West and Central Africa
}

\author{
H. D. Upadhyaya ${ }^{*}$, K. N. Reddy ${ }^{1}$, M. Irshad Ahmed ${ }^{1}$, C. L. L. Gowda ${ }^{1}$ \\ and B. I. G. Haussmann ${ }^{2}$ \\ ${ }^{1}$ International Crops Research Institute for the Semi-Arid Tropics (ICRISAT), \\ Genetic Resources, Crop Improvement, Patancheru, Andhra Pradesh 502 324, India \\ and ${ }^{2}$ ICRISAT, BP 12404, Niamey, Niger
}

Received 13 May 2009; Accepted 1 July 2009 - First published online 27 July 2009

\begin{abstract}
The International Crops Research Institute for the Semi-Arid Tropics (ICRISAT) genebank in India holds the world's largest collection of 21,594 pearl millet germplasm accessions including 18,447 landraces from 50 countries. West and Central Africa (WCA) region, which is considered as the centre of diversity for pearl millet, is also an important pearl millet germplasm source for resistance to biotic and abiotic stresses. A total of 7372 landraces were assembled from WCA countries. Out of which, 6434 landraces have the georeference data. The geographic origins of these landraces were analyzed using geographic information system tools to identify gaps in the collection. Geographical distribution of existing collections, type of vegetation, land cover and the high probability $(>70 \%)$ for the occurrence of pearl millet estimated using the FloraMap software in different countries show that 62 districts in 13 provinces of Nigeria, 50 districts in 16 provinces of Burkina Faso, 9 districts in 6 provinces each of Mali and Mauritania, 8 districts in 8 provinces of Chad and 7 districts in 3 provinces of Ghana as the major geographical gaps in the pearl millet collection at the ICRISAT genebank. In view of this, we suggest that the final areas for exploration in these districts should be decided prior to the launch of the collection missions in consultation with local government officials and extension officers, who have the knowledge of pearl millet cultivation in the districts identified.
\end{abstract}

Keywords: diversity; exploration; geographical gap; genetic resources

\section{Introduction}

Pearl millet (Pennisetum glaucum (L.) R. Br.) is an important food and forage crop in Africa and Asia, and used as forage in the Americas. It is a highly versatile crop with a high potential to become a valuable component of nontraditional agriculture. Interest in pearl millet is increasing because it grows well in poor dry land and sandy soils with

\footnotetext{
*Corresponding author. E-mail: h.upadhyaya@cgiar.org
}

few inputs, has high water use efficiency and can also be grown in more than one season with low production costs. The future importance of pearl millet is expected to increase under various climate change scenarios (Lane et al., 2007). It is currently mainly cultivated in Nigeria, Niger, Burkina Faso, Togo, Ghana, Mali, Senegal, Central African Republic, Cameroon, Sudan, Botswana, Namibia, Zambia, Zimbabwe and South Africa in Africa; and in India, Pakistan and Yemen in Asia.

Pearl millet is endowed with enormous genetic variability for various morphological, agronomic, food and nutritional traits. A wide genetic base is the key to the 
success of any crop improvement programme. In order to ensure the availability of large genetic variation to the crop improvement programmes, there is a need for collection, conservation, characterization, evaluation, documentation and distribution of plant genetic resources. Critical assessment of existing collections, identifying geographical gaps and launching germplasm collection missions in the unexplored and underexplored areas are important to enlarge the variability and achieve the completeness of collection.

The genebank at the International Crops Research Institute for the Semi-Arid Tropics (ICRISAT), India, holds the world's largest collection of 21,594 pearl millet germplasm accessions from 50 countries. Although the collection is impressive, exploration of pearl millet germplasm cannot be considered as complete. Being the primary centre of origin and domestication for pearl millet, West and Central Africa (WCA) could be the predominant source for highly diverse and adaptable pearl millet, which can be promising against biotic and abiotic stresses (Harlan, 1971; Harlan et al., 1975; Brunken et al., 1977).

Landraces, particularly the Iniadi, a prominent landrace mainly distributed in WCA countries such as Benin, Burkina Faso, Ghana and Togo, have remarkably contributed to the genetic improvement of pearl millet worldwide (Andrews and Anand Kumar, 1996). Most of the varieties bred at ICRISAT, India, are based on the Iniadi landrace germplasm. Preliminary screening of about 4900 pearl millet germplasm accessions at ICRISAT, India, revealed high frequencies of accessions from Mali (63.0\%), Niger (58.3\%), Senegal (47.0\%), Chad (43.8\%), and Ghana (39.3\%) as promising sources for downy mildew resistance. The genetic variability accumulated in the WCA region over centuries is at risk, mainly due to the introduction of improved varieties, climate change, concomitant natural catastrophes (droughts, floods, fire hazards etc), human settlements, overgrazing, destruction of plant habitats for irrigation projects etc (Upadhyaya and Gowda, in press). Although the pearl millet collection at ICRISAT genebank is fairly represented from all countries of WCA, there is a need to look for geographical gaps in the collection and assess the completeness of pearl millet germplasm collection. In the present study, the geographical distribution of existing pearl millet germplasm assembled from WCA at the ICRISAT genebank, India, was examined, and the geographical gaps were identified for possible exploration before potentially valuable material is lost forever.

\section{Materials and methods}

Being the world repository for the pearl millet germplasm, ICRISAT had made concerted efforts to introduce the pearl millet germplasm that was already assembled at different national and international institutes, universities and National Agricultural Research Systems (NARS) in different countries. A total of 65 organizations located in different countries contributed 10,764 accessions including those contributed by different disciplines at ICRISAT over years. ICRISAT and its partners planned for systematic collection of pearl millet germplasm in different countries and launched collection missions as per the priority areas identified in collaboration with the All India Coordinated Pearl Millet Improvement Project, National Bureau of Plant Genetic Resources and Agricultural Universities in India, and in collaboration mostly with International Board for Plant Genetic Resources [IBPGR, now Bioversity International (BI)], NARS, networks and universities in several other countries. So far, ICRISAT launched a total of 212 collection missions for all its mandate crops including pearl millet and collected 10,830 pearl millet germplasm accessions during 76 collection missions in 28 countries. The collection includes 18,447 landraces, 2268 breeding materials, 129 advanced cultivars and 750 accessions of wild relatives (Upadhyaya et al., 2007). A total of 8054 accessions including 7372 landraces are from WCA countries including Benin, Burkina Faso, Central African Republic, Cameroon, Chad, Ghana, Gambia, Mali, Mauritania, Niger, Nigeria, Senegal, Sierra Leone and Togo.

The present study initially considered 7372 pearl millet landraces assembled at ICRISAT genebank from all WCA countries. Passport data, particularly for information on precise location of collecting site and corresponding geographic coordinates, were updated by going through all related old records, collection reports and catalogues. Using Microsoft Encarta ${ }^{\circledR}$, an electronic atlas (MS Encarta ${ }^{\circledR}$ Interactive World Atlas, 2000), geographic coordinates were retrieved to fill the gaps for accessions having location information and the accuracy of coordinates was checked by plotting all accessions on political maps of each country. The final dataset consisted of 6434 accessions having the geographic coordinates' data. Complete passport data for these accessions are available at ICRISAT genebank, Patancheru, India.

FloraMap, a geographic information system (GIS) tool developed at Centro Internacional de Agricultura Tropical (CIAT), Columbia (Jones and Gladkov, 1999), was used to analyze the passport data and identify geographical gaps in the landrace germplasm collection from WCA countries. The basic input in the FloraMap software was the geographic coordinates (latitude and longitude) of the sampling site with a unique identifier (accession number). The FloraMap system is based on calculating the probability that a climate record belongs to a multivariate normal distribution described by the climates at the collection points of a calibration set of 
organisms. With user-friendly software linked to agroclimatic and other databases, biodiversity specialists can create maps showing the most likely distribution of any particular species in nature. FloraMap assigns climate data (monthly rainfall, minimum and maximum temperature and diurnal range in temperature) to each of the collection sites from the database provided along with the tool. Principal component analysis is used to reduce the dimensionality of this 36 dimensional dataset (set of 12 of the 3 variables) for each collection site and selects first few components that contribute to the maximum variation of the climatic characteristics. Also these few components are uncorrelated or orthogonal. Weights could be allocated to each of the three variables depending on the climate of the country/region. A probability density function is calculated on these few uncorrelated variables to find out the probability of finding a location for the population. While working on the passport dataset of pearl millet germplasm from WCA countries, equal weights were allocated to the three climatic variables (monthly rainfall, minimum and maximum temperature and diurnal range in temperature) and an exponential transformation with a power of $0.3-0.5$ depending on the country was applied to the monthly rainfall data. More than $95 \%$ of variation was explained by first four to seven principal components depending upon the country. The probability maps were generated for each country separately and the probabilities greater than $70 \%$ were considered for interpretation and recommendation for collection missions. While estimating the probability of pearl millet occurrence, multiple accessions with same coordinates were treated as a single collection site. Land cover map of Africa developed by United States Geological Survey (USGS) was used to know the type of vegetation and land cover in the areas of high probability (USGS EROS Center, 2005). Collection sites or sampled sites were overlaid on the probability image, and the districts with high-probability $(>70 \%)$ areas, which were unexplored or underexplored, have been identified as the major geographical gaps in the collection. All the districts identified in different countries were shown (shaded area) along with the collection sites of already collected accessions in the WCA map. Land cover and vegetation maps of Food and Agricultural Organization were considered while finalizing the districts for exploration in each country.

\section{Results}

The summary of pearl millet germplasm assembled from WCA countries (Table 1) indicated that ICRISAT and its partners had launched 12 germplasm collection missions in 10 WCA countries and collected a total of 2757 samples. The major collections included 1138 landraces in Nigeria during two collection missions launched in 1983 and 1992, followed by 750 accessions in Cameroon, 375 in Togo and 278 in Ghana. All landraces from Benin, Burkina Faso, Mauritania and Senegal were introductions in the ICRISAT genebank. A total of 4615 accessions originated in WCA countries were acquired from 12 organizations located in eight countries including ICRISAT subcentres in WCA countries and those in non-WCA countries. The Institut Français de Recherche

Table 1. Summary of pearl millet landrace germplasm assembled at ICRISAT genebank, Patancheru, India from West and Central Africa

\begin{tabular}{|c|c|c|c|c|c|c|c|}
\hline Country & $\begin{array}{l}\text { Collection } \\
\text { mission } \\
\text { code }\end{array}$ & Year & $\begin{array}{l}\text { No. of accessions } \\
\text { collected }\end{array}$ & $\begin{array}{l}\text { No. of accessions } \\
\text { introduced }\end{array}$ & Total & $\begin{array}{c}\text { No. of accessions } \\
\text { with georeference } \\
\text { data }\end{array}$ & $\begin{array}{c}\text { No. of } \\
\text { geographical } \\
\text { sites }\end{array}$ \\
\hline Benin & - & - & - & 46 & 46 & 46 & 27 \\
\hline Burkina Faso & - & - & - & 859 & 859 & 512 & 272 \\
\hline Cameroon & $\begin{array}{l}104 \\
128\end{array}$ & $\begin{array}{l}1983 \\
1985\end{array}$ & $\begin{array}{r}23 \\
727\end{array}$ & 159 & 909 & 909 & 239 \\
\hline $\begin{array}{l}\text { Central African } \\
\text { Republic }\end{array}$ & 167 & 1988 & 79 & 63 & 142 & 142 & 60 \\
\hline Chad & 154 & 1988 & 17 & 76 & 93 & 93 & 76 \\
\hline Gambia & 75 & 1980 & 15 & - & 15 & 15 & 11 \\
\hline Ghana & 83 & 1981 & 278 & - & 278 & 278 & 42 \\
\hline Mali & 174 & 1989 & 45 & 995 & 1040 & 1040 & 949 \\
\hline Mauritania & - & - & - & 5 & 5 & 4 & 4 \\
\hline Niger & 170 & 1989 & 1 & 999 & 1000 & 970 & 342 \\
\hline Nigeria & $\begin{array}{l}100 \\
199\end{array}$ & $\begin{array}{l}1983 \\
1992\end{array}$ & $\begin{array}{l}463 \\
675\end{array}$ & 892 & 2030 & 1537 & 443 \\
\hline Senegal & - & - & - & 376 & 376 & 339 & 200 \\
\hline Sierra Leone & 105 & 1983 & 59 & - & 59 & 59 & 21 \\
\hline Togo & 170 & 1989 & 375 & 145 & 520 & 490 & 120 \\
\hline
\end{tabular}


Scientifique pour le Développement en Coopération (ORSTOM, meanwhile called 'Institut de Recherche pour le Développement' (IRD), Paris, France, was the major donor (1988 accessions) of pearl millet landraces collected in Niger (576), Mali (431), Burkina Faso (308), Senegal (289), Cameroon (159), Togo (116), Central African Republic (63) and Benin (46). The IBPGR (now called BI), Rome, Italy, donated 667 accessions collected in Burkina Faso (492), Nigeria (128), Togo (29), Chad (14) and Mauritania (4). The Rockefeller Foundation, New Delhi, India, donated 487 accessions collected in Burkina Faso (22), Nigeria (263), Chad (62), Mali (52), Niger (45), Senegal (42) and Mauritania (1). Institut d'Economie Rurale (IER), Bamako, Mali collected in Mali (492); Ahmadu Bello University, Institute of Agricultural Research, Samaru collected in Nigeria (227); Centre National De Recherches Agronomiques, Bambey, Senegal collected in Senegal (58); United States Department of Agriculture and Southern Regional Plant Introduction Station, Griffin, Georgia, USA collected in Nigeria (120); and the Institute Nigerien Du Recherche Agronomique du Niger, Maradi, Niger collected in Niger (135) also donated their pearl millet collections to ICRISAT genebank. Subcentres of ICRISAT located at Bamako,
Mali; Niamey, Niger; and Ouagadougou, Burkina Faso, also launched germplasm collection missions and collected in Mali (20); Niger (242) and Nigeria (154); and Burkina Faso (37), respectively, and handed over the material to ICRISAT genebank at Patancheru, India.

A total of 6434 accessions had the information on geographic coordinates. All accessions from 8 out of 14 countries had the co-ordinates data. Accessions having georeference data represent a total of 2806 geographical sites of germplasm collection. As the FloraMap treated multiple accessions having same coordinates as a single collection site, the number of actual geographical sites with an area of $18 \times 18 \mathrm{~km}^{2}$ in the present study is less than the number of sampled sites. The collection from Mali recorded a maximum of 949 geographical sites out of 1040 sampling sites. Most of the accessions from Mali were the collections by the former ORSTOM, France; Rockefeller Foundation, India; and IER, Mali. Geographical distribution of existing collections indicated that almost all provinces having pearl millet cultivation, except Houet in Burkina Faso; Assaba, Brakna, Gorgol and Tagant in Mauritania; Gossas in Senegal; and Southern province in Sierra Leone, were explored and at least one sample was collected (Fig. 1; Table 2).

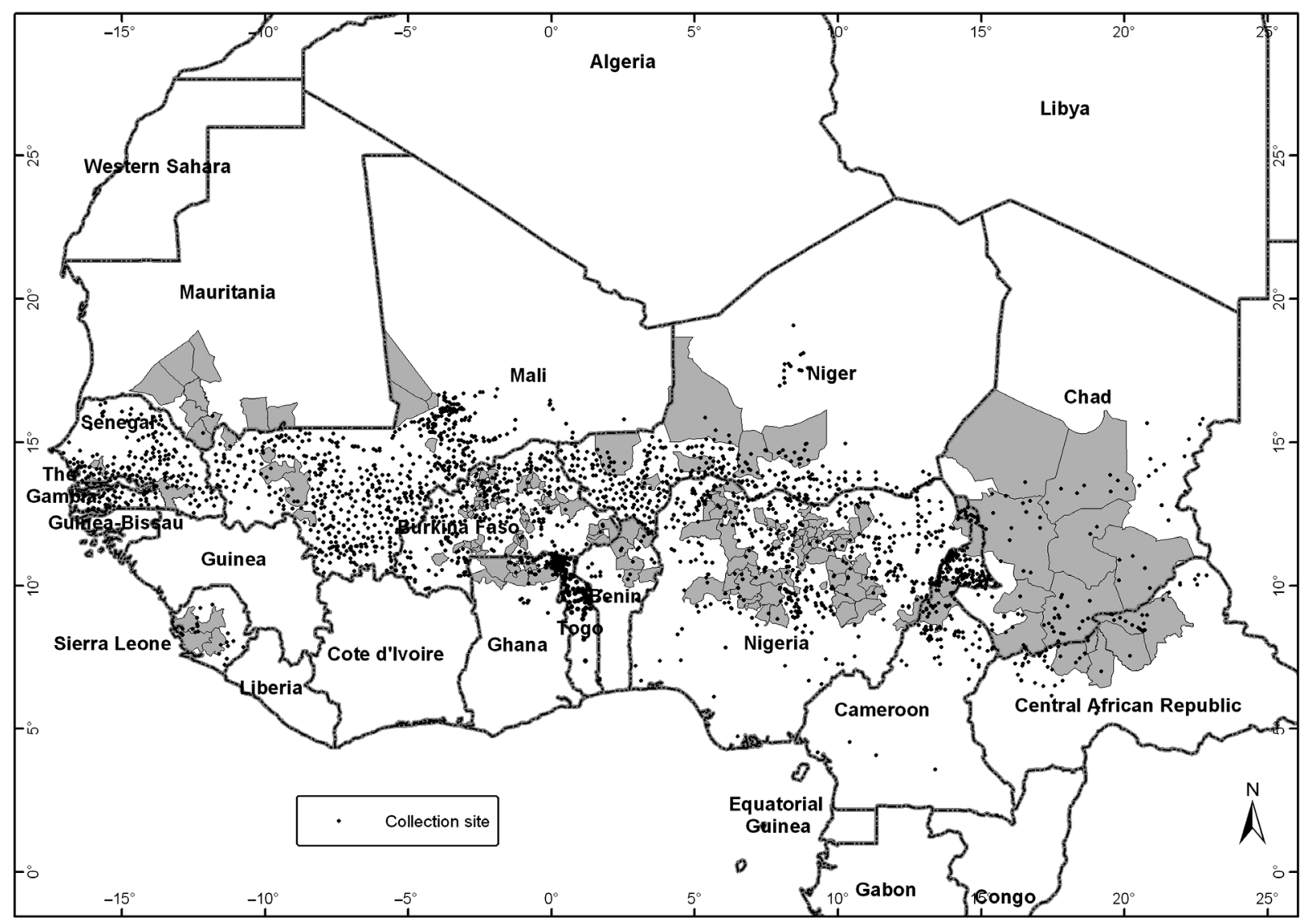

Fig. 1. Map showing geographical gaps (districts shaded) in the pearl millet germplasm from WCA countries and collection sites (dots) of germplasm presently conserved at the ICRISAT genebank, Patancheru, India. 
Table 2. Country wise provinces explored for pearl millet germplasm assembled at ICRISAT genebank, Patancheru, India

\begin{tabular}{|c|c|}
\hline Country & Provinces explored \\
\hline Burkina Faso & $\begin{array}{l}\text { Bam, Bazega, Bougouriba, Boulgou, Boulkiemde, Comoe, Ganzourgou, Gnagna, } \\
\text { Gourma, Houet, Kadiogo, Kenedougou, Kossi, Kouritenga, Mouhoun, Nahouri, } \\
\text { Namentenga, Oubritenga, Oudalan, Passore, Poni, Sanguie, Sanmatenga, Seno, } \\
\text { Sissili, Soum, Sourou, Tapoa, Yatenga, Zoundweogo }\end{array}$ \\
\hline Cameroon & $\begin{array}{l}\text { Province de Adamaoua, Province du Centre, Province de l'Est, Province de } \\
\text { I'Extrême-Nord, Province du Nord, Province du Sud-Ouest }\end{array}$ \\
\hline Chad & $\begin{array}{l}\text { Batha, Biltine, Borkou-Ennedi-Tibesti, Chari-Baguirmi, Guera, Kanem, Lake, Logone } \\
\text { Occidental, Logone Oriental, Mayo-Kebbi, Moyen-Chari, Ouaddai, Salamat, Tandjile }\end{array}$ \\
\hline Gambia & Maccarthy Island, North Bank, Upper River, Western \\
\hline Ghana & Northern, Upper East, Upper West \\
\hline Mali & $\begin{array}{l}\text { Ansongo, Bafoulabe, Banamba, Bandiagara, Bankass, Baraoueli, Bla, Bougouni, } \\
\text { Diema, Dioila, Dire, Djenne, Douentza, Gao, Goundam, Gourma-Rharous, } \\
\text { Kadiolo, Kangaba, Kati, Kayes, Kenieba, Kita, Kolokani, Kolondieba, Koro, } \\
\text { Koulikoro, Koutiala, Macina, Menaka, Mopti, Nara, Niafunke, Niono, Nioro, San, } \\
\text { Segou, Sikasso, Sokoto, Tenenkou, Tombouctou, Tominian, Yanfolila, Yelimane, } \\
\text { Yorosso, Youvarou }\end{array}$ \\
\hline Mauritania & Guidimaka, Hodh el Gharbi, Hodh ech Chargui \\
\hline Niger & Agadez, Diffa, Dossa, Maradi, Tahoua, Tillabery, Zinder \\
\hline Nigeria & $\begin{array}{l}\text { Adamwara, Bauchi, Benue, Borno, Cross River, Edo, FCT, Jigwa, Kaduna, Kano, } \\
\text { Katsina, Kebbi, Kogi, Kwara, Niger, Ogun, Osun, Oyo, Plateau, Rivers, Sokoto, } \\
\text { Taraba, Yobe }\end{array}$ \\
\hline Senegal & $\begin{array}{l}\text { Bakel, Bambey, Bignona, Dagana, Dakar, Fatick, Foundiougne, Kaffrine, Kaolack, } \\
\text { Kedougou, Kolda, Linguere, Louga, Matam, Mbacke, Mbour, Nioro du Rip, } \\
\text { Podor, Sedhiou, Tambacounda, Tivaouane, Upper River, Velingara }\end{array}$ \\
\hline Sierra Leone & Eastern, Northern, Southern, Western \\
\hline Togo & Centre, Kara, Northern, Plateaux, Savanes, Upper East \\
\hline
\end{tabular}

However, the high-probability area $(>70 \%)$ identified in different countries shows 62 districts of 13 provinces in Nigeria; 50 districts of 16 provinces in Burkina Faso; 9 districts of 6 provinces each of Mali and Mauritania; and 8 districts of 8 provinces in Chad as the major geographical gaps in the pearl millet collection at ICRISAT genebank, Patancheru, India (Fig. 1; Table 3). Seven districts in three provinces of Ghana that had shown high probability need exploration. Aftout (Barkewol) in Assaba province; Aleg and Magta-Lahjar districts in Brakna province; M'Bout district in Gorgol province and Moudjeria district in Tagant province of Mauritania; and Karankasso-Vigue district in Houet province of Burkina Faso were not explored in the past.

\section{Discussion}

Identification of geographical gaps using available passport information is essential to enlarge the existing collections in genebanks. Most of the older germplasm collections across the genebanks do not have complete passport information, particularly, the latitude and longitude of the colleting sites posing a problem in assessing the completeness of germplasm collections. Availability of georeference data helps in identifying the geographical gaps and enables the retrieval of the climate data for collecting sites, which is crucial in predicting the likely occurrence of a particular species in similar environment. Therefore, recording of latitude and longitude of collecting site is very important while collecting the germplasm.

Land cover and vegetation maps are also important in determining regions of crop cultivation and planning germplasm collection missions. Geographical distribution of past pearl millet collections in different countries indicated that the land covers like shrubland, irrigated crops, savannas, Sudanian woodlands, deforested savannas with crops, degraded forests' croplands, Acacia shrublands, grassland woodlands, savanna croplands and croplands with orchards are also the areas of pearl millet cultivation (USGS EROS Center, 2005). Therefore, based on the probability, land cover and type of vegetation, we can presume that the districts identified in the present study as the potential areas for exploration. The land cover in the provinces already explored in Mauritania is sparsely vegetated grassland, Sahel shrubs and shrubland. The land cover in the Karankasso-Vigue district of Burkina Faso is shrubland, irrigated crops and tree crops, indicating the possibility of pearl millet cultivation 
Table 3. Geographical gaps (districts) identified for exploration to collect pearl millet germplasm in West and Central Africa

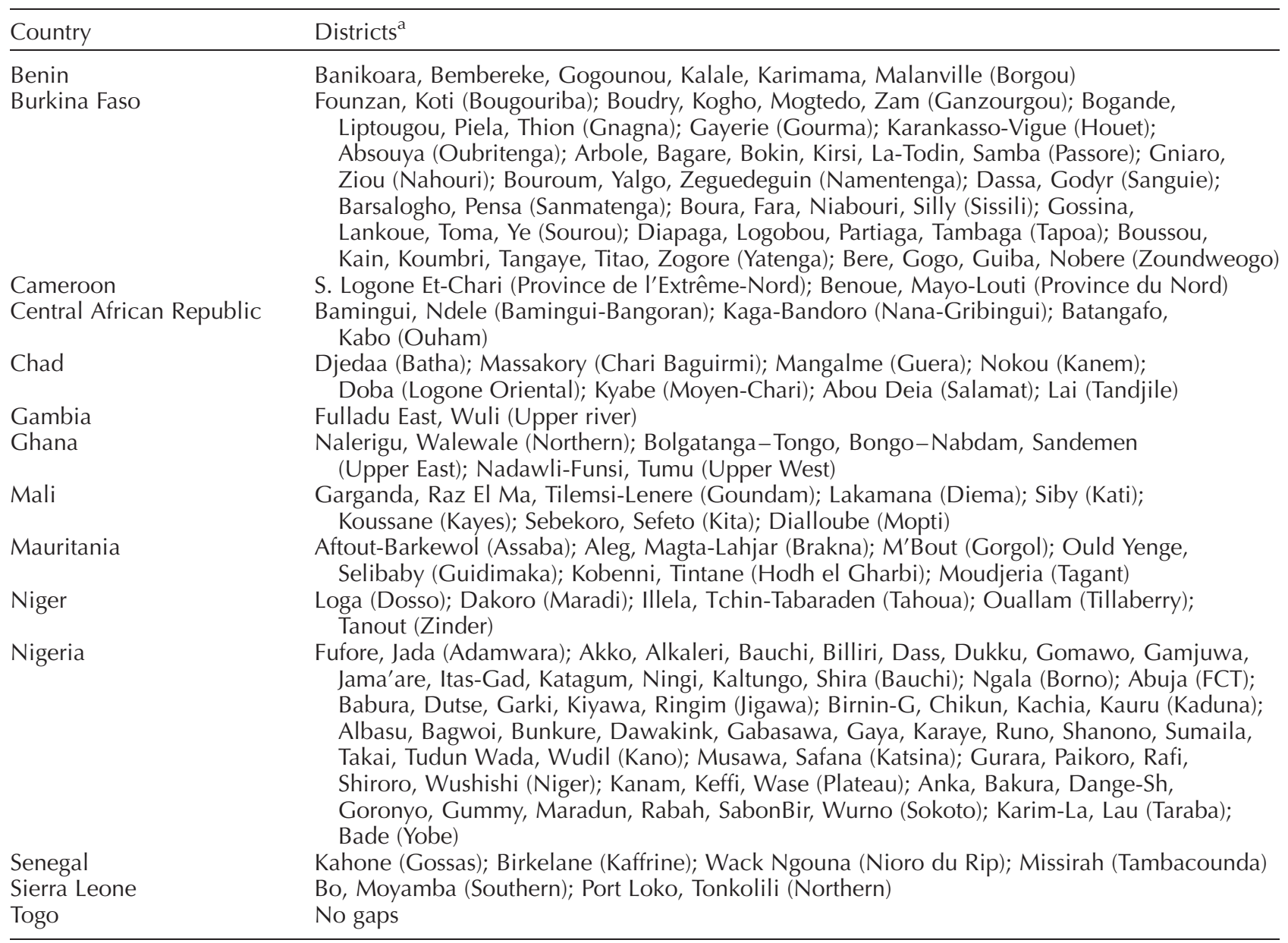

${ }^{\mathrm{a}}$ Names in the parenthesis are provinces.

in the unexplored districts. Interestingly, no geographical gaps were found in the collection from Togo, where the Iniadi landrace is predominant, indicating extensive collection of pearl millet germplasm in this country (Fig. 1; Table 3). Some of the districts identified in the present study were explored partly in the past and a few samples were collected. ICRISAT and partners had launched all its germplasm collection missions prior to 1993, and hence it is likely that new landraces might have evolved and adapted in the underexplored areas. Therefore, recollection in these underexplored areas cannot be considered as duplicate collection.

It is essential to know the potential distribution and climatic adaptation of pearl millet in order to identify geographical gaps in the germplasm collections and to augment the existing collections by collecting germplasm before the valuable material may be lost forever. Considering the importance of assessing completeness of germplasm collections, it is recommended that the germplasm collectors should record the georeference data (latitude, longitude and altitude) of all collecting sites while sampling the germplasm. Using the georeference data, we can retrieve the information on environmental conditions of the collection sites, which is normally associated with the patterns of genetic variability (Marilia et al., 2003). This additional information is very useful in ecogeographic stratification of landraces and their utilization in crop improvement. GIS tools provide more precise cartographic representation of the ecogeographic regions and of the germplasm-collecting sites (Marilia et al., 2003). Although the gaps identified using FloraMap in the present study provide valuable information, it is suggested that the final area for exploration should be decided prior to the launch of the collection mission in consultation with local government officials, NARS scientists, extension officers and non-governmental organizations, who will have the knowledge about the extent of pearl millet cultivation in the districts. It is also suggested that the exploration team leader should review all reports and publications of past collections in 
these countries to prepare collection plans for districts (gaps) identified in the present study. As ICRISAT had not launched any collection mission in the past exclusively for wild relatives, germplasm collection plans for the identified gaps should target both cultivated as well as wild relatives' germplasm of pearl millet.

\section{Acknowledgements}

Authors sincerely acknowledge the contribution of all former and present staff of Genetic Resources Unit (GRU), ICRISAT, in collection, assembly and conservation of pearl millet genetic resources. The help of Mr D. Bapa Rao, Senior Research Technician, GRU in processing and documentation of the data for this study is highly appreciated.

\section{References}

Andrews DJ and Anand Kumar K (1996) Use of the West African pearl millet landrace Iniadi in cultivar development. Plant Genetic Resources Newsletter 105: 15-22.

Brunken JN, de Wet JMJ and Harlan JR (1977) The morphology and domestication of pearl millet. Economic Botany 31: $163-174$.

Harlan JR (1971) Agricultural origins: centers and non-centers. Science 14: 468-474.
Harlan JR, de Wet JMJ and Stemler ABL (1975) Plant domestication and indigenous African agriculture. In: Harlan JR, de Wet JMJ and Stemler ABL (eds) Origins of African Domestication. The Hague, The Netherlands: Mouton Publishers, pp. 1-9.

Jones PG and Gladkov A (1999) In: Jones Annie L and CD-ROM series (eds) FloraMap: A Computer Tool for Predicting the Distribution of Plants and Other Organisms in the Wild. Version 1. Cali, Colombia: Centro Internacional de Agricultura, Tropical (CIAT)

Lane A, Jarvis A and Atta-Krah K (2007) The impact of climate change on crops and crop areas and the role of agricultural biodiversity in adaptation. International Symposium on Climate Change, November 22-24, 2007, ICRISAT, Patancheru, India, SAT ejournal 4(1). Available online only at ejournal.ICRISAT.org.

Marilia Lobo Burle, Torres Cordeiro Celia Maria, Fonseca Jaime Roberto, Palhares de Melo M, de Belemdas Neves Alves Rosa and Abadie Tabare (2003) Characterization of germplasm according to environmental conditions at the collecting site using GIS - two case studies from Brazil. Plant Genetic Resources Newsletter 135: 1-11.

MS Encarta ${ }^{\circledR}$ Interactive World Atlas 20001995-1999 Microsoft Corporation. One Microsoft way, Redmond, WA, USA.

Upadhyaya HD and Gowda CLL (in press) Managing and enhancing the use of germplasm - strategies and methodologies. Technical Manual no. 10. Patancheru, India: International Crops Research Institute for the Semi-Arid Tropics.

Upadhyaya HD, Reddy KN and Gowda CLL (2007) Pearl millet germplasm at ICRISAT genebank - status and impact. The Journal of Semi-Arid Tropical Agricultural Research (SAT ejournal) 3(1): 1-5.

USGS EROS Center (2005) Africa land cover characteristics database. 